\title{
DETERMINATION OF BIOGENIC AMINES BY USING AMPEROMETRIC BIOSENSORS BASED ON GRASS PEA AMINE OXIDASE AND OAT POLYAMINE OXIDASE
}

\section{LAURA AQUILANTEE,b, ${ }^{\mathrm{a}}$, MIHAELA NISTOR ${ }^{\mathrm{a}, 2}$, STEFANIA TAORMINA ${ }^{\mathrm{a}, 3}$, MAREK ŠEBELA ${ }^{c}$, IVO FRÉBORT', IONEL CĂTĂLIN POPESCU ${ }^{\text {b, }}{ }^{*}$}

\begin{abstract}
Grass pea amine oxidase (GPAO) and oat polyamine oxidase (OPAO) were immobilized along with horseradish peroxidase (HRP) and an Os-redox polymer (Os-RP) onto the surface of a graphite electrode by crosslinking with poly(ethylenglycol) diglycidyl ether. The resulted reagentless amperometric biosensors were inserted in a flow injection setup and used as electrochemical detectors for the biogenic amines (BA) detection. Both biosensors were operated at low applied potential $(-50 \mathrm{mV}$ vs. $\mathrm{Ag} / \mathrm{AgCl}$, $\mathrm{KCl}_{0.1 \mathrm{M}}$ ) where electrochemical interferences are minimal. The quantification of ten BA (tyramine, putrescine, cadaverine, histamine, cystamine, phenylethylamine, agmatine, tryptamine, spermine, and spermidine) either individual or in mixture (after a preliminary separation by using cation exchange chromatography) was reported. G/(Os-RP)-HRP-GPAO biosensor detected all ten BA, while G/(Os-RP)-HRP-OPAO biosensor detected only spermine and spermidine. Finally, a simple and low-cost method for free and acetylated polyamines determination in human urine samples, by using the highly selective G/(Os-RP)-HRP-OPAO biosensor, was proposed.
\end{abstract}

Keywords: Amine oxidase, polyamine oxidase, amperometric reagentless biosensors, biogenic amines, human urine

a Lund University, Department of Analytical Chemistry, P.O. Box 124, SE-22100 Lund, Sweden

${ }^{1}$ Present address: British School of Geneva, Avenue de Châtelaine 95A, CH-1219 Vernier, Geneva, SWITZERLAND

2Present address: Bioprocess Control Sweden AB, Scheelevägen 22, SE-22363 Lund, SWEDEN

${ }^{3}$ Present address: London Health Coaching, 52 Dulwich road, SE24 OPA London, UNITED KINGDOM

${ }^{\mathrm{b}}$ Babeş-Bolyai University, Faculty of Chemistry and Chemical Engineering, 11 Arany Janos str., RO-400028, Cluj-Napoca, Romania

c Palacký University Olomouc, Centre of the Region Haná for Biotechnological and Agricultural Research, Šlechtitelů 27, CZ-78371, Olomouc, CZECH REPUBLIC

*Corresponding author: cpopescu@chem.ubbcluj.ro 
LAURA AQUILANTE, MIHAELA NISTOR, STEFANIA TAORMINA, MAREK ŠEBELA, IVO FRÉBORT, IONEL CĂTĂLIN POPESCU

\section{INTRODUCTION}

Biogenic amines (BA) are organic bases present in a wide range of food products and living organisms deriving mainly from microbial decarboxylation of amino acids or from amination and transamination of aldehydes and ketones [1]. Histamine (Hist), putrescine (Put), cadaverine (Cad), tyramine (Tyra), tryptamine (Trypt), phenylethylamine (PEA) and agmatine (Agm) are among the most important BA in food. Polyamines like spermine (Spm) and spermidine (Spd) are found only in small quantities in food like legumes and meat, but they take part in growth and development of cells [2, 3]. However, it has been demonstrated that high amounts of Spm and Spd in blood and urine are reliable markers for cancer therapy monitoring [4].

Oxidation of BA can be catalyzed by different types of amine oxidases (AOs). AOs are widely spread in bacteria, fungi, higher plants and animals [5]. Copper-containing AOs catalyze the oxidative deamination of BA, generating the corresponding aldehyde, ammonia and hydrogen peroxide [6, 7]. The reaction of flavin-containing polyamine oxidases (PAOs) results in the production of an aminoaldehyde (alternatively, typically in plants, they may form 1,3-propanediamine, 1,3-pn) and hydrogen peroxide, but not in ammonia $[7,8]$. Plant PAOs show very restricted substrate specificity, oxidizing only Spm and Spd including their $N$-acetyl derivatives $[4,5]$.

The determination of BA by enzymatic analysis using AOs and PAOs was previously studied. For example, the use of PAOs immobilized in reactors $[9,10]$ or cross-linked with glutaraldehyde onto electrochemical biosensors [11] as well as electrochemical enzyme probes based on oxygen electrodes and AOs [12] have been reported in the literature.

AOs-based amperometric biosensors for biogenic amines detection were formerly developed, both in single [13-16] and coupled enzyme-based designs (with peroxidase) [16, 17-20]. The single AO-based biosensors required high applied potentials ( $>200 \mathrm{mV}$ vs. Ag/AgCl), which can lead to high background currents and interfering signals when complex matrices are analyzed. At the same time, the bienzyme electrodes, operated at lower applied potentials ( -50 or $0 \mathrm{mV}$ vs. $\mathrm{Ag} / \mathrm{AgCl}$ ) allowed a considerably reduction of the matrix interferences. However, such devices have a major drawback because they are not able to discriminate between different BA due to the low selectivity of the detecting AO used.

Various chromatographic techniques are frequently applied for separation of biogenic amines. Among these techniques HPLC [21-23], thin layer chromatography [24] or electrophoresis [25] are the most frequently used. Thin layer chromatography is simple and inexpensive but requires extensive analysis time and the obtained results are only semi-quantitative. 
Capillary electrophoresis has been a popular tool for BA separation, but since the BA could not be detected directly in a sensitive manner [25], HPLC became a better alternative.

In a previous work [26], a new analytical system based on coupling a weak cation exchange column with an AO-based amperometric biosensor for determination of biogenic amines, with application in food analysis, was described.

Here we report on the construction and assembling of a highly specific and sensitive amperometric biosensor for polyamines incorporating polyamine oxidase from oat seedlings (OPAO), denoted G/(Os-RP)-HRPOPAO, and its potential application in biomedical analysis. At the same time, the extended use of a previously reported amperometric biosensor [26], based on amine oxidase from grass pea (GPAO) (denoted G/(Os-RP)-HRPGPAO) is discussed. A comparison between the two amperometric biosensors has been performed under similar experimental conditions.

Thus, both OPAO and GPAO were cross-linked to horseradish peroxidase (HRP) and an Os-based redox polymer (Os-RP) by using the poly(ethylenglycol) diglycidyl ether and were immobilized onto the surface of solid graphite $(\mathbf{G})$. The detection of BA has been carried out amperometrically, by monitoring the $\mathrm{H}_{2} \mathrm{O}_{2}$ generated by the enzymatic reaction. At first, both biosensors, operated at a low applied potential $\left(-50 \mathrm{mV} v \mathrm{~s}\right.$. $\left.\mathrm{Ag} / \mathrm{AgCl}, \mathrm{KCl}_{0.1 \mathrm{M}}\right)$, were integrated in a single line flow injection (FI) setup. Further, the amperometric detection was coupled with a cation-exchange column and the method was optimized for the separation and quantification of ten BA (Tyra; Put; Cad; Hist; cystamine, i.e. Cyst; PEA; Agm; Trypt; Spm and Spd) from a synthetic mixture. Finally, preliminary experiments were carried out by using G/(Os-RP)-HRP-OPAO biosensor to estimate the content of Spd and Spm in sample of human urine.

\section{RESULTS AND DISCUSSION}

A bienzymatic approach, based on GPAO or OPAO in combination with HRP, was considered for biosensors development. The biosensor design involved the immobilization of both enzymes (i.e., the oxidase and the peroxidase) on solid graphite, and the detection was carried out by mediated electron-transfer using an Osmium-based redox polymer (Os-RP). The detection principle of the resulting biosensors is schematically presented in Figure 1. Due to the presence of Os-RP and to the low applied potential (-50 $\mathrm{mV}$ vs. $\mathrm{Ag} / \mathrm{AgCl}, \mathrm{KCl}_{0.1} \mathrm{~m}$ ), this approach confers simultaneously a high sensitivity and an excellent selectivity to the amperometric measurements. 


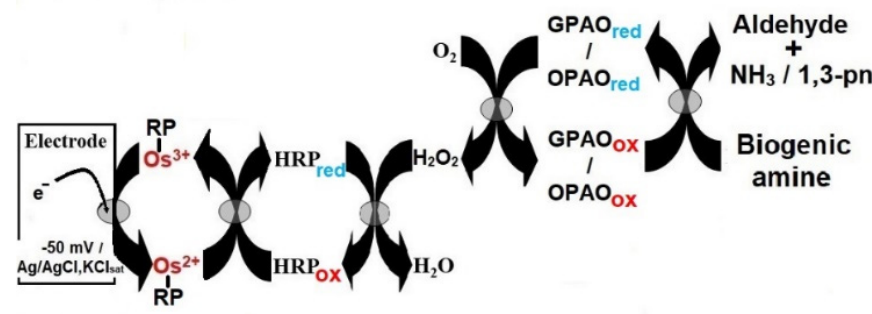

Figure 1. Detection principle of biogenic amines at G/(Os-RP)-HRP-GPAO and G/(Os-RP)-HRP-OPAO reagentless amperometric biosensors.

Individual calibration curves for ten BA (Tyra, Put, Cad, Hist, PEA, Cyst, Agm, Spd, Trypt and Spm) were recorded at both developed biosensors, G/(Os-RP)-HRP-GPAO and G/(Os-RP)-HRP-OPAO, in a single line FI setup (Figure 2).
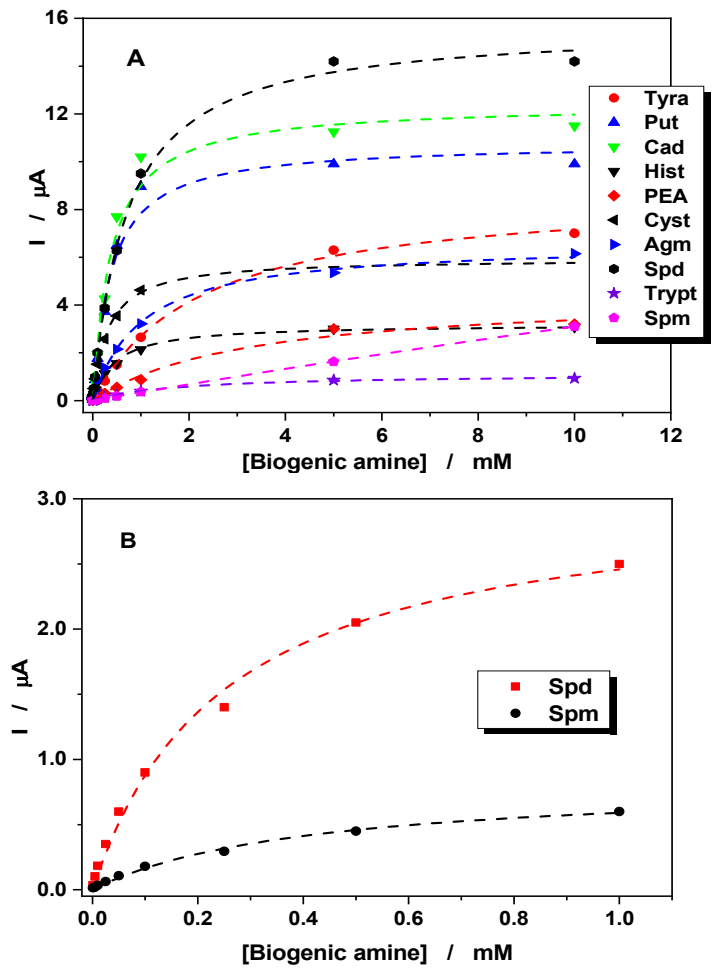

Figure 2. Calibration curves for different biogenic amines obtained at G/(Os-RP)-HRPGPAO (A) and G/(Os-RP)-HRP-OPAO (B) biosensors, by using FI measurements.

Experimental conditions: supporting electrolyte, $0.1 \mathrm{M}$ phosphate buffer $(\mathrm{pH} 7.2)$; applied potential, $-50 \mathrm{mV}$ vs. $\mathrm{Ag} / \mathrm{AgCl}, \mathrm{KCl}_{0.1}$;; flow rate, $0.5 \mathrm{~mL} / \mathrm{min}$; injection loop, $100 \mu \mathrm{L}$; dispersion coefficient of the FI setup, 2. 
The G/(Os-RP)-HRP-GPAO biosensor responded to all tested amines (Figure 2A), whereas G/(Os-RP)-HRP-OPAO biosensor could only detect Spm and Spd (Figure 2B), proving that GPAO is an enzyme with a much broader selectivity than OPAO.

As expected, the calibrations curves recorded for all tested amines follow a Michaelis-Menten pattern. The main kinetic $\left(\mathrm{K}_{\mathrm{M}}\right.$, Michaelis-Menten constant; I $I_{\max }$ maximum current intensity) and analytical parameters (linear range, sensitivity -estimated as the slope of the linear domain-, and detection limit), were calculated from the calibration curves shown in figure 2 and are summarized in Table 1. It can be stated that, under the specified FI conditions, the sensitivities observed at the GPAO based biosensor decrease in the following sequence:

$$
(\text { Spd } \approx \text { Cad } \approx \text { Cyst })>\text { Put }>\text { Agm }>\text { Hist }>\text { Tyra }>\text { PEA }>\text { Trypt }>\text { Spm }
$$

It is worth noticing that, for both investigated enzymes, the highest sensitivities correspond to the lowest Michaelis-Menten constants (Table 1). This fact suggests that, for the actual biosensor design, a high substrate-enzyme affinity can be considered as the main factor determining the biosensor sensitivity.

Next, G/(Os-RP)-HRP-GPAO and G/(Os-RP)-HRP-OPAO biosensors were alternatively coupled to a single line $\mathbf{F I}$ setup incorporating a cationexchange column. A synthetic mixture containing all investigated BA was injected in the chromatographic column and the biosensor signal was recorded. In this way, by using the cation-exchange chromatography the BA mixture was firstly separated in its components and, subsequently, each resulted individual BA was detected by the biosensor used as a chromathographic electrochemical detector (Figure 3).

When the G/(Os-RP)-HRP-GPAO biosensor was used as chromatographic detector, the chromatogram recorded for a mixture of ten BA (Tyra, Put, Cad, Hist, PEA, Cyst, Agm, Spd, Trypt and Spm) evidences a complete separation of the initial mixture (Figure $3 A$ ). Contrarily, the G/(Os-RP)-HRP-OPAO biosensor was able to detect only Spd and Spm (Figure 3B). The total time spent for analysis was $\sim 53 \mathrm{~min}$. The sudden decrease of the baseline occurring around the $35^{\text {th }}$ minute is due to an increase of the carrier concentration from 16 to $24 \mathrm{mM}$. 
Table 1. Kinetic and analytical parameters for BA detection recorded at G/(Os-RP)-HRP-GPAO and G/(Os-RP)-HRP-OPAO biosensors used in FI setup. For experimental conditions see Figure 2.

\begin{tabular}{|c|c|c|c|c|c|}
\hline BA & $\begin{array}{c}\mathrm{K}_{\mathrm{M}}^{*} \\
(\mathrm{mM})\end{array}$ & $\begin{array}{c}\mathbf{I}_{\text {max }}{ }^{*} \\
(\mu \mathrm{A})\end{array}$ & $\begin{array}{c}\text { Linear } \\
\text { range }(\mu \mathrm{M})\end{array}$ & $\frac{\text { Sensitivity }(\mu \mathrm{A} / \mathrm{mM})}{\mathbf{R}^{2} / \mathbf{N}^{* *}}$ & $\begin{array}{c}\mathbf{D L}^{* * *} \\
(\mu \mathrm{M})\end{array}$ \\
\hline Tyra & $2.2 \pm 0.2$ & $8.8 \pm 0.2$ & $5-1000$ & $\frac{2.64 \pm 0.08}{0.9928 / 9}$ & 2.7 \\
\hline Put & $0.38 \pm 0.06$ & $10.8 \pm 0.4$ & $1-500$ & $\frac{13.1 \pm 0.4}{0.9929 / 8}$ & 0.5 \\
\hline Cad & $0.38 \pm 0.06$ & $12.4 \pm 0.5$ & $1-500$ & $\frac{15.6 \pm 0.4}{0.9958 / 8}$ & 0.4 \\
\hline Hist & $0.45 \pm 0.04$ & $3.2 \pm 0.1$ & $1-100$ & $\frac{7.3 \pm 0.3}{0.9939 / 6}$ & 0.8 \\
\hline PEA & $3.2 \pm 0.6$ & $4.5 \pm 0.3$ & $1-500$ & $\frac{1.06 \pm 0.03}{0.9960 / 8}$ & 0.5 \\
\hline Cyst & $0.31 \pm 0.02$ & $5.9 \pm 0.2$ & $1-100$ & $\frac{15.0 \pm 0.7}{0.9906 / 6}$ & 0.4 \\
\hline Agm & $1.01 \pm 0.07$ & $6.6 \pm 0.1$ & $1-100$ & $\frac{8.27 \pm 0.04}{0.9998 / 6}$ & 0.7 \\
\hline Spd & $0.71 \pm 0.04$ & $15.7 \pm 0.3$ & $1-250$ & $\frac{15.5 \pm 0.8}{0.9874 / 7}$ & 0.4 \\
\hline Trypt & $1.8 \pm 0.1$ & $\begin{array}{c}1.12 \pm \\
0.02\end{array}$ & $25-1000$ & $\frac{0.39 \pm 0.02}{0.9884 / 9}$ & 15.4 \\
\hline Spm & $79 \pm 8.0$ & $28 \pm 2.0$ & $25-10000$ & $\frac{0.310 \pm 0.003}{0.9993 / 11}$ & 19.4 \\
\hline \multicolumn{7}{|c|}{$\mathbf{G / ( O s - R P ) - H R P - O P A O}$} \\
\hline Spd & $0.25 \pm 0.03$ & $3.1 \pm 0.1$ & $1-50$ & $\frac{11.3 \pm 0.6}{0.9916 / 5}$ & 0.5 \\
\hline Spm & $0.40 \pm 0.05$ & $\begin{array}{c}0.83 \pm \\
0.05\end{array}$ & $5-100$ & $\frac{1.68 \pm 0.06}{0.9940 / 6}$ & 3.6 \\
\hline
\end{tabular}

${ }^{*} \mathrm{~K}_{\mathrm{M}}$ and $\mathrm{I}_{\max }$ were estimated from the Michaelis-Menten non-linear fitting of the calibration curves (Figures 2A and 2B)

${ }^{* *} \mathrm{R}$, correlation coefficient; $\mathrm{N}$, number of experimental points ${ }^{* * *} \mathrm{DL}$ was estimated for a signal/noise ratio equal to 3 . 

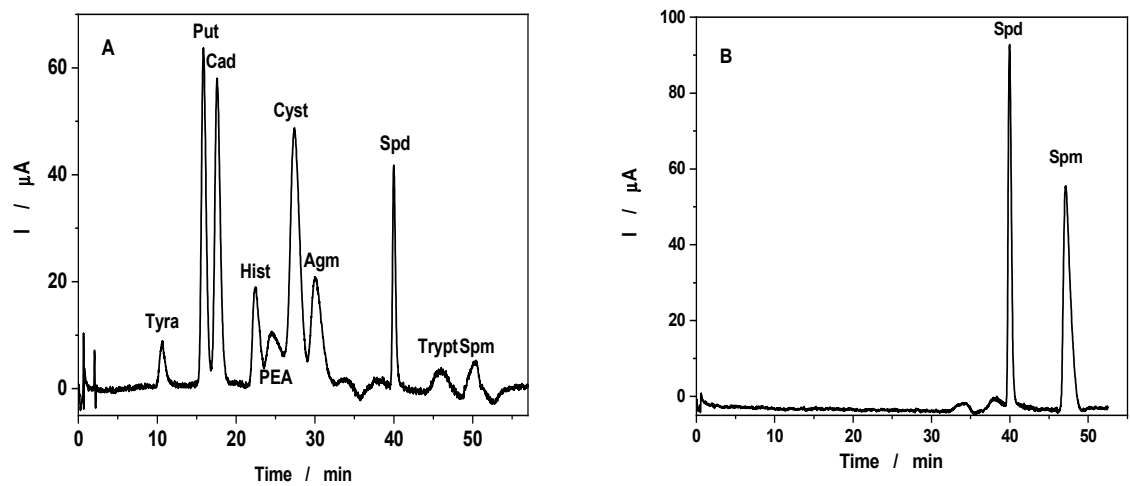

Figure 3. Chromatographic separation of a synthetic mixture of 10 biogenic amines by using G/(Os-RP)-HRP-GPAO (A) and G/(Os-RP)-HRP-OPAO (B) as amperometric detectors. Retention times: (A): Tyra (10.62 min), Put (15.83 min), Cad (17.58 min), Hist (22.45 min), PEA (24.51 min), Cyst (27.38 min), Agm (29.95 min), Spd (39.98 min), Trypt (46.22 min), and Spm (50.00 min); (B): Spd (39.95 min) and Spm (47.13 min). Experimental conditions: applied potential, $-50 \mathrm{mV}$ vs. $\mathrm{Ag} / \mathrm{AgCl}, \mathrm{KCl}_{0.1} \mathrm{~m}$; flow rate, $1.8 \mathrm{~mL} \mathrm{~min}^{-1}$; injection loop, $50 \mu \mathrm{L} ;$ [Put], [Cad], [Cyst], and [Spd] were $100 \mu \mathrm{M}$; [Tyr], [Hist] and [Agm] were $200 \mu \mathrm{M}$; [PEA] was $500 \mu \mathrm{M}$; [Trypt] and [Spm] were $1 \mathrm{mM}$; flow carrier, 12 mM MSA.

The electrochemical detection of biogenic amines, carried out after their separation by using high performance liquid chromatography, was found much more efficient than the ultraviolet detection [27, 28]. However, in these studies the separated amines were quantified by oxidation at unmodified electrodes poised at substantial positive potentials $(+700 \mathrm{mV}$ and $+400 \mathrm{vs}$. $\mathrm{Ag} / \mathrm{AgCl}$, respectively). Aiming to show the efficiency of the developed biosensors, the amperometric responses observed for Spd at G/(Os-RP)HRP-GPAO and G/(OS-RP)-HRP-OPAO were compared with those recorded at bare graphite electrodes, poised at two different applied potentials (Figure $4)$.

As it can clearly be seen from Figure 4, the bare graphite electrode, even poised at a relatively high positive potential $(+550 \mathrm{mV} v \mathrm{~s}$. $\mathrm{Ag} / \mathrm{AgCl}$, $\mathrm{KCl}_{0.1 \mathrm{M}}$ ), is practically insensitive to the Spd presence. Contrarily, both biosensors are highly sensitive to Spd, G/(Os-RP)-HRP-GPAO being the most efficient. Moreover, due to the low applied potential, the Spd detection at both biosensors is practically without electrochemical interferences. 


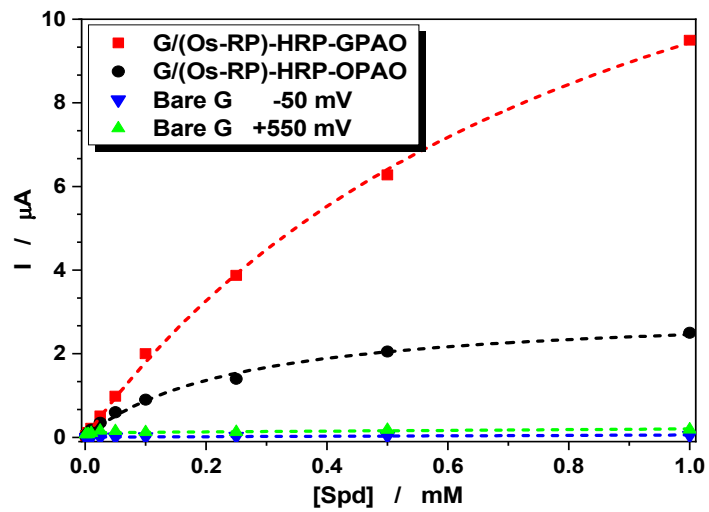

Figure 4. Spd amperometric detection at G/(Os-RP)-HRP-GPAO, G/(Os-RP)HRP-OPAO biosensors and bare graphite electrodes (G) operated at two different applied potentials. Experimental conditions: supporting electrolyte, $0.1 \mathrm{M}$ phosphate buffer containing $0.1 \mathrm{M} \mathrm{KCl}(\mathrm{pH} 7.2)$; biosensors applied potential, $-50 \mathrm{mV} v s$. $\mathrm{Ag} / \mathrm{AgCl}, \mathrm{KCl} 0.1 \mathrm{M}$; flow rate, $0.5 \mathrm{~mL} / \mathrm{min}$; injection loop, $100 \mu \mathrm{L}$; dispersion coefficient of the FI setup, 2.

It is worth mentioning, that the response of the G/(Os-RP)-HRP-OPAO biosensor was examined for the acetylated Spm and Spd (AcSpm and AcSpd), since Spm and Spd are frequently found in these forms in real samples (Figure 5). The biosensor was found sensitive to both acetylated polyamines (AcSpm, $\mathrm{K}_{\mathrm{M}}=136.5 \pm 33.8 \mu \mathrm{M} ; \mathrm{I}_{\max }=67.2 \pm 5.9 \mathrm{nA} ;$ AcSpd, $\mathrm{K}_{\mathrm{M}}=120.7 \pm 50.0 \mu \mathrm{A}$; $I_{\max }=28.1 \pm 3.3 \mathrm{nA}$ ), but the signals were $\sim 10$ and $\sim 100$ times smaller than those corresponding to the unacetylated amines, respectively.

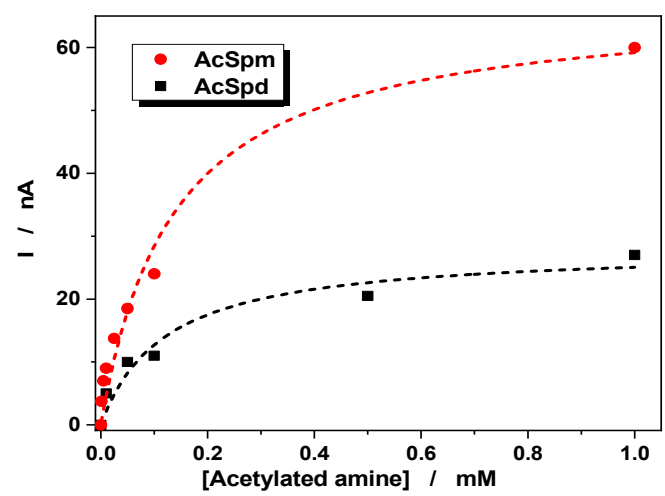

Figure 5. Calibration curves for AcSpm and AcSpd recorded at G/(Os-RP)HRP-OPAO biosensor by using FI amperometric measurements. Experimental conditions: supporting electrolyte, $0.1 \mathrm{M}$ phosphate buffer $(\mathrm{pH} 7.2)$; applied potential, $-50 \mathrm{mV} v$ s. $\mathrm{Ag} / \mathrm{AgCl}, \mathrm{KCl} 0.1 \mathrm{M}$; flow rate, $0.5 \mathrm{~mL} / \mathrm{min}$; injection loop, $100 \mu \mathrm{L}$; dispersion coefficient of the FI setup, 2. 
As a proof of concept, taking into account that the presence in human urine of high amounts of Spm and Spd and their $\mathrm{N}$-acetylated forms are markers for a serious illness (e.g. cancer, osteoporosis, or hepatic cirrhosis) [9], some preliminary investigations using the G/(Os-RP)-HRP-OPAO biosensor were performed in order to estimate the polyamine content in real samples of human urine. Because polyamines exist in urine mainly in their conjugated form, an acid hydrolysis was carried out before the detection to ensure that all polyamines are present in their free form.

Due to the low concentrations of Spm and Spd that normally exist in the urine of healthy persons, they were not detected in fresh urine samples by using the G/(Os-RP)-HRP-OPAO amperometric biosensor coupled to a cation exchange column. However, the biosensor in contact with hydrolyzed samples of urine provided a signal $\approx 40$ times higher than that corresponding to the non-hydrolyzed urine, indicating significant concentrations of acetylated polyamines (AcSpm and AcSpd). In order to facilitate the comparison, the estimated concentrations of Spd and Spm were expressed in $\mathrm{mg} / \mathrm{L}$ urine and in $\mathrm{mg} / \mathrm{g}$ creatinine, as well (Table 2). The obtained values were found similar to those reported in the literature [29], suggesting the suitability of the developed method for clinical assays.

Table 2. Spermine and spermidine concentrations in hydrolyzed human urine samples estimated by using the G/(Os-RP)-HRP-OPAO amperometric biosensor and FI measurements. For experimental conditions see Figure 5.

\begin{tabular}{|c|c|c|c|c|}
\hline $\begin{array}{c}\text { Biogenic } \\
\text { amine }\end{array}$ & $\mathbf{m M}$ & $\mathbf{m g} / \mathbf{L}$ urine & $\mathbf{m g} / \mathbf{g}$ creatinine & Obs. \\
\hline Spm & $0.80 \pm 0.06$ & $162 \pm 13$ & $0.19 \pm 0.001$ & Female $(20$ \\
\cline { 1 - 3 } Spd & $1.20 \pm 0.05$ & $174 \pm 7$ & $0.20 \pm 0.001$ & years) \\
\hline Spm & $1.00 \pm 0.09$ & $202 \pm 19$ & $0.24 \pm 0.002$ & Male \\
Spd & $0.60 \pm 0.05$ & $87 \pm 8$ & $0.10 \pm 0.001$ & (23 years) \\
\hline
\end{tabular}

${ }^{*}$ The creatinine concentration in the urine samples was $0.12 \mathrm{~g} / \mathrm{dL}$

\section{CONCLUSIONS}

The chromatographic separation and electrochemical detection of ten BA (Tyra, Put, Cad, Hist, PEA, Cyst, Agm, Spd, Trypt and Spm) from a synthetic mixture were attempted in order to prove the full functionality of two amperometric biosensors, G/(Os-RP)-HRP-GPAO and G/(Os-RP)-HRPOPAO, as electrochemical detectors for liquid chromatography. At the same time, the kinetic and analytical parameters of both biosensors were estimated by using the data shown in the calibration curves. 
Irrespective of the BA nature, the G/(Os-RP)-HRP-GPAO biosensor showed a broad selectivity, a good linear response with low detection limits (from $0.4 \mu \mathrm{M}$ for Spd, Cad and Cyst, to $20 \mu \mathrm{M}$ for Spm) and upper limits of quantification ranging from $100 \mu \mathrm{M}$ (Hist, Cyst, Agm) to $10 \mathrm{mM}$ (Spm). Interestingly, the G/(Os-RP)-HRP-OPAO biosensor was found much more selective detecting only Spm and Spd.

Finally, the G/(Os-RP)-HRP-OPAO biosensor was used to estimate the polyamines content in human urine, after their hydrolysis with $\mathrm{NaOH}$. Thus, an attempt for a simple and low-cost method for BA detection in biological fluids, suitable for clinical analysis was made.

\section{EXPERIMENTAL SECTION}

\section{Reagents}

Amine oxidase (EC 1.4.3.22) from grass pea (Lathyrus sativus) (GPAO) and polyamine oxidase (EC 1.5.3.14) from oat (Avena sativa) seedlings (OPAO) were isolated and purified according to previously published protocols [30, 31]. Horseradish peroxidase (EC 1.11.1.7) was purchased from Sigma Chem. Co. (St. Louis, MO, USA) as a lyophilized powder with an activity of $1100 \mathrm{U} / \mathrm{mg}$ solid. As described elsewhere [32], the osmium redox polymer (Os-RP) was prepared by complexing poly(1-vinyl imidazole) with $[\mathrm{Os}(4,4$ 'dimethylbipyridine) $\left.{ }_{2} \mathrm{Cl}\right]^{2+}$. Poly(ethylenglycol) (400) diglycidyl ether (PEGDGE) from Polysciences (Warrington, PA, USA) was used for the cross-linking of the bienzyme mixtures, i.e. GPAO-HRP or OPAO-HRP, to Os-RP.

Histamine dihydrochloride (Hist), tyramine hydrochloride (Tyra), putrescine dihydrochloride (Put), cystamine dihydrochloride (Cyst), agmatine sulfate (Agm), spermine phosphate salt (Spm) and spermidine phosphate hexahydrate (Spd) were obtained from ICN Biochemicals Inc. (Aurora, $\mathrm{OH}$, USA). Cadaverine dihydrochloride (Cad), $\mathrm{N}$-acetylspermidine dihydrochloride (AcSpd) and $\mathrm{N}$-acetylspermine trihydrochloride (AcSpm) were purchased from Sigma (St. Louis, MO, USA) whereas tryptamine hydrochloride (Trypt) and 2-phenylethylamine hydrochloride (PEA), were received from Fluka Chemie (Buchs, Switzerland). Methanesulfonic acid (>99\%) (MSA) was supplied by Sigma-Aldrich (Poole, UK) and hydrochloric acid (32\%) by Merck (Darmstadt, Germany).

For flow injection (FI) measurements and chromatographic separation, standard solutions with concentrations ranging from 0.1 to $5000 \mu \mathrm{M}$ were daily prepared by diluting the stock solutions of biogenic amines $(10 \mathrm{mM}$ in $0.1 \mathrm{M}$ phosphate buffer) with $0.1 \mathrm{M}$ phosphate buffer or aqueous solution of 12 mM MSA, respectively. 
Disodium hydrogen phosphate dehydrate, potassium dihydrogen phosphate and sodium chloride purchased from Merck (Darmstadt, Germany) were utilized to prepare the $0.1 \mathrm{M}$ phosphate buffer $(\mathrm{pH} 7.2)$, which was used as flow carrier in the FI setup or to neutralize the acidic effluent from the chromatographic column. Before usage, the buffer solution was filtered through a $0.45 \mu \mathrm{m}$ filter type HA (Millipore, Molshem, France) and thoroughly degassed.

If not otherwise indicated, all solutions were prepared in purified water obtained from a Milli-Q system (Millipore, Bedford, MA, USA).

\section{Equipment}

A single line flow-injection (FI) system, consisting of a manual injection valve (Valco Instruments Co. Inc., Houston, TX, USA) with an injection loop of 100 $\mu \mathrm{L}$, a peristaltic pump (Alitea AB, Stockholm, Sweden), a wall-jet electrochemical cell, a low current potentiostat (Zäta-Elektronik, Höör, Sweden) and a single channel chart recorder (Model BD 111, Kipp \& Zonen, Delft, The Netherlands), was used to operate the amperometric biosensors. The "Peaksimple" software (SRI Instruments, Torrance, CA, USA) was employed for the data acquisition.

The tubing connecting the peristaltic pump to the flow-through electrochemical cell was made of teflon $(0.5 \mathrm{~mm}$ i.d.). The enzyme-modified graphite electrode was the working electrode. $\mathrm{An} \mathrm{Ag} / \mathrm{AgCl}, \mathrm{KCl}_{0.1 \mathrm{~m}}$ electrode and a Pt wire were used as reference electrode and counter electrode, respectively.

The chromatographic system consisted of a gradient HPLC pump (Varian, Varian Inc., USA), an injector with a loop of $50 \mu \mathrm{L}$, a weak acid cation exchange analytical column (IonPac CS-17, Dionex, Sunnyvale, CA, USA; $250 \times 4 \mathrm{~mm}$; particle size $7 \mu \mathrm{M}$ ), and a pre-column lonPac (GC-17 Guard column, Dionex, Sunnyvale, CA, USA; $50 \times 4 \mathrm{~mm}$; particle size $7 \mu \mathrm{M})$. The optimal gradient profile used was the following: from 0 to $30 \mathrm{~min}$ ( $8 \mathrm{mM}$ MSA); from 32 to $34 \mathrm{~min}$ (16 mM MSA); from 36 to $44 \mathrm{~min}$ (24 mM MSA).

The biosensors, used as electrochemical detectors, were incorporated in the chromatographic system by coupling the effluent of the analytical column to the electrochemical cell, as described elsewhere [26]. In order to neutralize the acidic effluent before coming in contact with the amine oxidase based-biosensor, a post-column T-connection was used to mix the column eluate $\left(0.9 \mathrm{~mL} \mathrm{~min}^{-1}\right)$ with a secondary flow containing phosphate buffer $\left(0.9 \mathrm{~mL} \mathrm{~min}^{-1}\right)$.

\section{Biosensor preparation}

Prior to the modification, the rods of spectroscopic graphite (RingsdorffWerke $\mathrm{GmbH}$, Bonn-Bad, Germany, type RW001, $3.05 \mathrm{~mm}$ diameter) were polished on a wet fine emery paper (Tufback, Durite P1200, Allar, Sterling Heights, MI). 
In the case of G/(Os-RP)-HRP-GPAO electrode $5 \mu \mathrm{L}$ of a mixture containing $2.5 \mathrm{mg} / \mathrm{mL}$ GPAO, $2.5 \mathrm{mg} / \mathrm{mL}$ HRP, $1 \mathrm{mg} / \mathrm{mL}$ Os-RP, and $1 \mathrm{mg} / \mathrm{mL}$ PEGDGE were placed on the top of a graphite electrode and left 1 day to dry at room temperature.

Similarly, in the case of G/(Os-RP)-HRP-OPAO electrode $5 \mu \mathrm{L}$ of a mixture containing $2 \mathrm{mg} / \mathrm{mL}$ OPAO, $2 \mathrm{mg} / \mathrm{mL}$ HRP, $0.8 \mathrm{mg} / \mathrm{mL}$ Os-RP, and $0.8 \mathrm{mg} / \mathrm{mL}$ PEGDGE were deposited on the top of a graphite electrode and left 1 day to dry at room temperature.

\section{Real samples preparation}

The extraction of polyamines from urine was performed as previously described by Lipton et al. [33]: $1 \mathrm{~mL}$ of $10 \mathrm{M} \mathrm{HCl}$ was added to $1 \mathrm{~mL}$ of urine, pre-filtered through a $0.2 \mu \mathrm{m}$ filter (Millipore) and then hydrolyzed with $\mathrm{NaOH}$ for $15 \mathrm{~h}$ at $110^{\circ} \mathrm{C}$.

The hydrolyzed urine was evaporated to dryness on a Buchler rotary evaporator (Buchler Instruments Div., Searle Diagnostics Inc., Fort Lee, N. J.) and reconstituted in $1 \mathrm{~mL}$ of wat er. The same hydrolysis procedure was carried out for $1 \mathrm{~mL}$ of AcSpm, AcSpd and buffer (as control experiments).

\section{ACKNOWLEDGEMENTS}

L. A. gratefully acknowledges Romanian National Council of Research in Higher Education (CNCSIS) for financial support (research grant TD 267/2007-2008).

\section{REFERENCES}

1. M.H. Silla Santos, Int. J. Food Microbiol., 1996, 29, 213-231.

2. S. Bardocz, Trends Food Sci. Technol., 1995, 6, 341-346.

3. P. Kalac, P. Krausova, Food Chem., 2005, 90, 219-230.

4. L. Scarciglia, D. Compagnone, G. Federici, G. Palleschi, Analusis, 1998, 26, 219-223.

5. M. Šebela, A. Radova, R. Angelini, P. Tavladoraki, I. Frébort, P. Pec, Plant Sci., 2001, 160, 197-207.

6. M.A. Medina, J.L. Urdiales, C. Rodríguez-Caso, F.J. Ramírez, F. SánchezJiménez, Crit. Rev. Biochem. Molec. Biol., 2003, 38, 23-59.

7. A. Toninello, P. Pietrangeli, U. De Marchi, M. Salvi, B. Mondovi, Biochim. Biophys. Acta, 2006, 1765, 1-13. 
DETERMINATION OF BIOGENIC AMINES BY USING AMPEROMETRIC BIOSENSORS BASED ON GRASS PEA AMINE OXIDASE AND OAT POLYAMINE OXIDASE

8. D.L. Morgan, Biochem. Soc. Trans., 1985, 13, 322-326.

9. K. Hiramatsu, S. Kamei, M. Sugimoto, K. Kinoshita, K. Iwasaki, M. Kawakita, J. Biochem., 1994, 115, 584-589.

10. N. Watanabe, Biomed. Chromatogr., 1992, 6, 1-3.

11. M. Esti, G. Volpe, L. Massignan, D. Compagnone, E. La Notte, G. Palleschi, J. Agric. Food Chem., 1998, 46, 4233-4237.

12. I. Karube, I. Satoh, Y. Araki, S. Suzuki, H. Yamada, Enz. Microb. Technol., $1980,2,117-120$

13. R. Draisci, G. Volpe, L. Lucentini, A. Cecilia, R. Federico, G. Palleschi, Food Chem., 1998, 62, 225-232.

14. R. Gasparini, M. Scarpa, M.L. Di Paolo, R. Stevanato, A. Rigo, Bioelectrochem. Bioenerg., 1991, 25, 307-315.

15. M. Niculescu, T. Ruzgas, C. Nistor, I. Frébort, M. Šebela, P. Pec, E. Csoregi, Anal. Chem., 2000, 72, 5988-5993.

16. S. Tombelli, M. Mascini, Anal. Chim. Acta, 1998, 358, 277-284.

17. R. Gasparini, M. Scarpa, F. Vianello, B. Mondovi, A. Rigo, Anal. Chim. Acta, 1994, 294, 299-304.

18. M. Niculescu, C. Nistor, I. Frébort, P. Pec, B. Mattiasson, E. Csoregi, Anal. Chem., 2000, 72, 1591-1597.

19. M. Wimmerova, L. Macholan, Biosens. Bioelectron., 1999, 14, 695-702.

20. T.J. Castilho, M.d.P.T. Sotomayor, L.T. Kubota, J. Pharm. Biomed. Anal., 2005, 37, 785-791.

21. A. Onal, Food Chem., 2007, 103, 1475-1486.

22. M.Y. Khuhawar, G.A. Qureshi, J. Chromatogr. B, 2001, 764, 385-407.

23. G. Taibi, M.R. Schiavo, M.C. Gueli, P. Calanni Rindina, R. Muratore, C.M.A. Nicotra, J. Chromatogr. B, 2000, 745, 431-437.

24. K.A. Khan, Chromatogr., 2006, 64, 423-427.

25. S. Oguri, J. Chromatogr. B, 2000, 747, 1-19.

26. L. Muresan, R. Ronda Valera, I. Frébort, I.C. Popescu, E. Csoregi, M. Nistor, Mikrochim. Acta, 2008, 163, 219-225.

27. D. Bose, A. Durgbanshi, M.E. Capella-Peiro, M. Gil-Agusti, J. Esteve-Romero, S. Carda-Broch, J. Pharm. Biomed. Analysis, 2004, 36, 357-363.

28. C.A. Heidbreder, L. Lacroix, A.R. Atkins, A.J. Organ, S. Murray, A. West, A.J. Shah, J. Neurosci. Methods, 2001, 112, 135-144.

29. H. Inoue, K. Fukunaga, S. Munemura, Y. Tsuruta, Anal. Biochem., 2005, 339, 191-197.

30. M. Šebela, L. Luhova, I. Frébort, H.G. Faulhammer, S. Hirota, L. Zajoncova, V. Stuzka, P. Pec, Phytochem. Anal., 1998, 9, 211-222.

31. J. Stranska, M. Šebela, P. Tarkowski, P. Rehulka, J. Chmelik, I. Popa, P. Pec, Biochim., 2007, 89, 135-144.

32. T.J. Ohara, R. Rajagopalan, A. Heller, Anal. Chem., 1994, 66, 2451-2457.

33. A. Lipton, L.M. Sheehan, G.F. Kessler, Cancer, 1975, 35, 464-468. 